\title{
Decision Support System integrated with Geographic Information System to target restoration actions in watersheds of arid environment: A case study of Hathmati watershed, Sabarkantha district, Gujarat
}

\author{
Dhruvesh P Patel ${ }^{1,2}$, Prashant K Srivastava ${ }^{3, *}$, \\ MANIKA GUPTA ${ }^{4}$ and NARESH NANDHAKUMAR ${ }^{5}$ \\ ${ }^{1}$ Department of Civil Engineering, Dr Jivraj Mehta Institute of Technology, Mogar 388 306, India. \\ ${ }^{2}$ Department of Civil Engineering, Saffrony Institute of Technology, Mehsana 384 435, India. \\ ${ }^{3}$ WEMRC, Department of Civil Engineering, University of Bristol, Bristol, United Kingdom. \\ ${ }^{4}$ Department of Civil Engineering, Indian Institute of Technology, New Delhi 110 016, India. \\ ${ }^{5}$ WTI Advance Technology Limited, Chennai 600 086, Tamil Nadu, India. \\ ${ }^{*}$ Corresponding author.e-mail: prashant.just@gmail.com
}

\begin{abstract}
Watershed morphometric analysis is important for controlling floods and planning restoration actions. The present study is focused on the identification of suitable sites for locating water harvesting structures using morphometric analysis and multi-criteria based decision support system. The Hathmati watershed of river Hathmati at Idar taluka, Sabarkantha district, Gujarat is experiencing excessive runoff and soil erosion due to high intensity rainfall. Earth observation dataset such as Digital Elevation Model and Geographic Information System are used in this study to determine the quantitative description of the basin geometry. Several morphometric parameters such as stream length, elongation ratio, bifurcation ratio, drainage density, stream frequency, texture ratio, form factor, circularity ratio, and compactness coefficient are taken into account for prioritization of Hathmati watershed. The overall analysis reveals that Hathmati comprises of 13 mini-watersheds out of which, the watershed number 2 is of utmost priority because it has the highest degradation possibilities. The final results are used to locate the sites suitable for water harvesting structures using geo-visualization technique. After all the analyses, the best possibilities of check dams in the mini-watersheds that can be used for soil and water conservation in the watershed are presented.
\end{abstract}

\section{Introduction}

Watershed describes an area of land that contains a common set of streams and rivers that all drain into a single large body of water (Black 2005). It is a natural entity that helps to dispose the runoff through a single outlet (Betson 1964). However, Chow (1964) defined watershed as the separating boundary of a drainage basin and termed it as a catchment. Watershed management implies the sensible use of the natural resources in a watershed to ensure optimum and sustained productivity (Yadav et al. 2014). It is the process of formulating and carrying out a course of actions involving manipulation of the natural subsystem of watersheds to achieve specified objectives (Aher et al. 2014).

Keywords. Morphometric analysis; remote sensing; Geographic Information System; prioritization; water harvesting structure; multi-criteria evaluation. 
For sustainable management of watersheds, soil erosion is a major factor, which accelerates the rate of land degradation and hence influences agricultural productivity, runoff movement, and sometimes leads to flood in the lower basin (Essiet 1990). It further implies appropriate use of land and water resources of a watershed for optimum production with minimum hazard to natural resources (Kessler et al. 1992; Osborne and Wiley 1988). Water harvesting structures play a major role to limit these type of losses and ensure sustainable measurements through the construction of artificial water harvesting structures such as check dams, farm ponds, nalla (small drains) bunds, percolation tanks, terracing, waterways, and contour tillage. To strengthen this approach, the Soil and Water Conservation Division, Ministry of Agriculture, Government of India launched an integrated watershed management programme in a direction to conserve soil and water in degraded regions. The programme offered great potential in improving land and water resources by integrating recent development and indigenous traditional knowledge in the technical literature domain (Singh et al. 2009) with expectation that this holistic approach will not only conserve soil and water resources but also enhance the crop yield and support the economy.

Remote Sensing (RS) coupled with Geographical Information System (GIS) techniques proved to be an efficient tool in drainage delineation and morphometric analysis (Chopra et al. 2005; Bali et al. 2012; Magesh et al. 2012; Banerjee and Srivastava 2014). GIS facilitates database creation for the watershed, helping decision makers in framing appropriate measures for critically affected areas (Thakkar and Dhiman 2007; Bali et al. 2012; Srivastava et al. 2012c). It was also found to be an effective tool not only for collection, storage, management and retrieval of a multitude of spatial and non-spatial data (Srivastava et al. 2012b; Srivastava et al. 2013), but also for spatial analysis and integration of these data to derive useful outputs and modelling (Mukherjee et al. 2009; Srivastava et al. 2011). One of the useful applications of GIS is towards watershed prioritization, which refers to the ranking of different mini-watersheds according to the order of development. By prioritization of watersheds, one can conclude which watershed can lead to higher amount of discharge due to excessive amount of rainfall and erosion (Edet et al. 1998; Chowdary et al. 2009; Javed et al. 2009, 2011). Several researchers have also demonstrated the use of earth observation datasets and GIS for determining the suitable sites for water harvesting structures by overlaying of DEM, soil map, and slope maps (Javed et al. 2009, 2011; Patel et al. 2012). Nooka Ratnam et al. (2005) proposed check dam positioning by prioritization of micro watersheds using Sediment Yield Index (SYI) and morphometric analysis. Further in 2007, Thakkar and Dhiman prioritized the Mohr watershed, lying between Sabarkantha and Kheda districts, Gujarat, India. Recently, Patel et al. (2012) presented a case study to select suitable sites for water harvesting structures in Varekhadi watershed, a part of Lower Tapi Basin (LTB), Surat district, Gujarat by overlaying of Digital Elevation Model (DEM) from Shuttle Radar Topography Mission, soil map, and slope map, using morphometric analysis.

Watershed geo-visualization is a promising technique to understand many natural phenomena like flood and erosion occurring in the watershed (Buttenfield and Mackaness 1991; Patel and Srivastava 2013). It has been characterized as a kind of GIS with emphasis on the individuals using interactive visual tools in the search for the unknown (MacEachren and Taylor 1994). By prioritization of watersheds, one can conclude which watershed can lead to higher amount of discharge due to excessive rainfall (Patel 2012). In the present study, the prioritization concept (Khan et al. 2001) is used to understand morphology of Hathmati watershed integrated with the multicriteria based decision support system (Gupta and Srivastava 2010; Srivastava et al. 2012c) to locate the ideal sites for water harvesting structure positioning such as check dams with the following aims: It will (1) check the excessive water from watershed that cause flash floods in the region; (2) support the soil and water conservation services; (3) provide restoration measures to government officials for severely degraded miniwatersheds; (4) boost the water potential for irrigation as well as for domestic usage. Most of the papers published in the technical literature domain, have only considered compound factors for locating harvesting structures with and without ranking and weight methodology. However, for appropriate identification of water harvesting structures using ranking and weight methodology, an Analytical Hierarchical Principle (AHP) based multi-criteria evaluation (MCE) decision matrix could be used for checking the consistency of their weight and to avoid misjudgements in the weighing assignment. Through this study, a new approach to the watershed management will be provided, which can be used for locating water harvesting structures efficiently, and in a more reasonable way. In this study, the water harvesting structures are proposed by integrating the morphometric based compound factors along with the other thematic maps using the GIS weighted overlay techniques following AHP-MCE. 


\section{Materials and methods}

\subsection{Study area and agro-climatic description}

The Hathmati watershed lies between $23^{\circ} 50^{\prime} 40^{\prime \prime}$ to $24^{\circ} 02^{\prime} 00^{\prime \prime} \mathrm{N}$ and $72^{\circ} 44^{\prime} 51^{\prime \prime}$ to $73^{\circ} 15^{\prime} 04^{\prime \prime} \mathrm{E}$, covering a total area of $1085.66 \mathrm{~km}^{2}$ (figure 1). According to 1:50,000 scale map of Survey of India (SOI), most of the area falls into the topographical sheet numbers $46 \mathrm{~A} / 13,14,46 \mathrm{E} / 01,02$. It is considered as hot arid/semi-arid region in western India and experiences hot summer from March to mid-June. The maximum dry temperature ranges between $42^{\circ}$ and $45^{\circ} \mathrm{C}$. The region encompasses three distinct seasons: winter, summer, and monsoon. The temperature increases from January onwards having maximum values during May and gradually decreases afterwards. The wind direction is predominantly towards northeast during the months November to March. During May and the first week of June, the winds have westerly component. With the onset of monsoon, southwest winds are strong and humid, with relative humidity more than $60 \%$. The region is predominately inhabited by the tribal population, which till a few decades ago mainly depended on forests for its livelihood, now also practices subsistence agriculture for food and fodder. Though well irrigation has a long history in the region, the extent of irrigation is very low. The recharge of wells occurs at a very slow pace due to socio-economic conditions and overuse or because of the arid climate and excessive evapotranspiration from the surface.

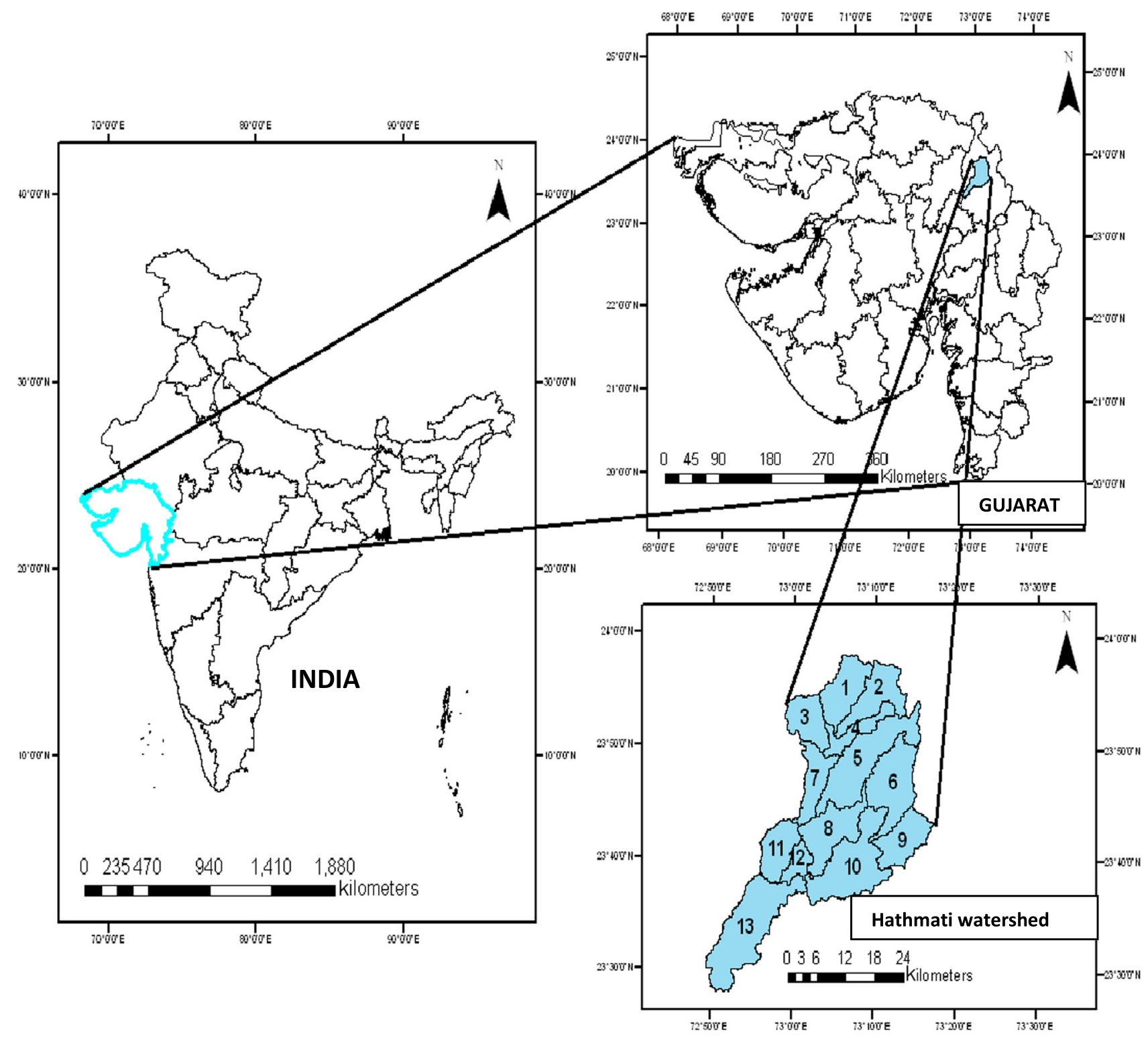

Figure 1. Location map of the study area. 


\subsection{Spatial datasets used in this study}

\subsubsection{Geology and geomorphology}

The region mainly consists of secondary group or Mesozoic with Purana system (Algonkian and part of Cambrian). The main rock type is Erinpura granite (post-Delhi) with approximate age of 1500 million years (figure 2a). These granites were first recorded in Erinpura, Rajasthan, and thus named after it. These rocks are foliated in nature except for quartzite, which is blocky and hard. Because of hard rocks, recharge by rainfall is very poor which makes groundwater storage limited in this area. Quartz-porphyry or quartz feldspar porphyry, a rock similar to granite in appearance occurs in this area, and in the Indrasi Valley near Hathmati dam. The spatial resolutions of the geology and geomorphology maps are very small, so the other less prominent features cannot be visualised using the maps. However, to distinguish the Hathmati watershed, previous ground survey reports are taken into account to elaborate the less dominant features existing over the terrain. Geomorphologically (figure $2 \mathrm{~b}$ ), the area depicts both erosional and depositional landform features of Proterozoic era with epoch Neo-Proterozoic. The super group formation of this region corresponds to Syn-to-Oist Delhi intrusive (www.gmdcltd.com). A large area is covered by unconsolidated sand, silt, and clay with sporadic occurrence of isolated hills and ranges. The other parts of the area are covered with semiconsolidated boulder pebbles and sand with occurrence of undulated upland and subdued hills in the west part (GEC 1992).

\subsubsection{Drainage network}

Drainage can be defined as the entire geographical area drained by a river and its tributaries, found to be an important parameter for flood control in most of the basins. Drainage delineation tool using SRTM is used here to delineate the drainage in the study area and the same is corrected by comparing it with digitized SOI topographical sheets in GIS environment. After drainage delineation, drainage density is calculated using the Arc GIS 9.1 software. Afterwards, Horton (1945) stream ordering technique is used to give order numbers to each stream (figure 2c).

\subsubsection{Digital elevation model and slope of mini-watersheds}

The Shuttle Radar Topography Mission (SRTM) $\mathrm{C}$ band radar data is used to derive the Digital Elevation Model (DEM) and slope of the miniwatersheds. The spatial resolution of the DEM obtained from SRTM is $90 \mathrm{~m}$. 3D analyst tool is used to visualize the SRTM DEM, represented in figure 2(d). From this DEM, a categorised slope map is generated following the surface analysis and slope-percentage function (figure 3 ). Slopes in this study are classified on the basis of the guidelines mentioned in Integrated Mission for Sustainable Development (IMSD) document (IMSD 1995). In the study area, slopes can be categorized as: Level to nearly level $(0-1 \%)$, very gently sloping $(1-3 \%)$, gently sloping (3-8\%), moderately sloping (8-15\%) and moderately steep sloping (15-30\%).

\subsubsection{Soil map of the area}

Soil map prepared by the National Bureau of Soil Survey and Land Use Planning (NBSS \& LUP), NRIS (National Resources Information System), and Department of Agriculture, Gujarat State, Ahmedabad are used in this study. Different types of soil have different capacities for retaining rainwater. In the study area, the dominant soil types that exist are clayey, clayey skeletal, coarse loamy, fine, fine loams, loamy, loamy skeletal, and very fine (figure 4). Generally, clayey soil causes higher flooding than other types of the loamy group.

\subsection{Morphometric analysis and water harvesting structures positioning}

Arc GIS 9.1 software is used for the preparation of primary thematic layers for Hathmati watershed. All the input datasets were geo-referenced to the World Geodetic System 1984 (WGS84) coordinate system. The considered layers of governing factors are integrated and analysed, as the datasets derived have different degrees of influence on positioning check dam structures. Following IMSD (IMSD 1995), the criteria for possible location of check dams are: (I) slope should be less than $3 \%$, (II) land use may be barren, shrub land, or riverbed, (III) infiltration rate of the soil should be less, and (IV) type of soil should be sandy/ gravel/clay loam. Moreover, in the present study, the morphometric based compound factor has also been taken into account following IMSD guidelines to provide a more realistic estimation of the watershed hydrologic response.

In this method, the total weights of the final integrated polygons are derived as the sum of the product of the weights assigned to the different layers according to their suitability. The miniwatersheds delineated layer is used to obtain basic morphometric parameters such as area $(A)$, perimeter $(P)$, length $(L)$, number of streams $(N)$. Basin length $\left(L_{b}\right)$ is calculated from stream length, while the bifurcation ratio $\left(R_{b}\right)$ is calculated from the number of streams. Other linear and shape 

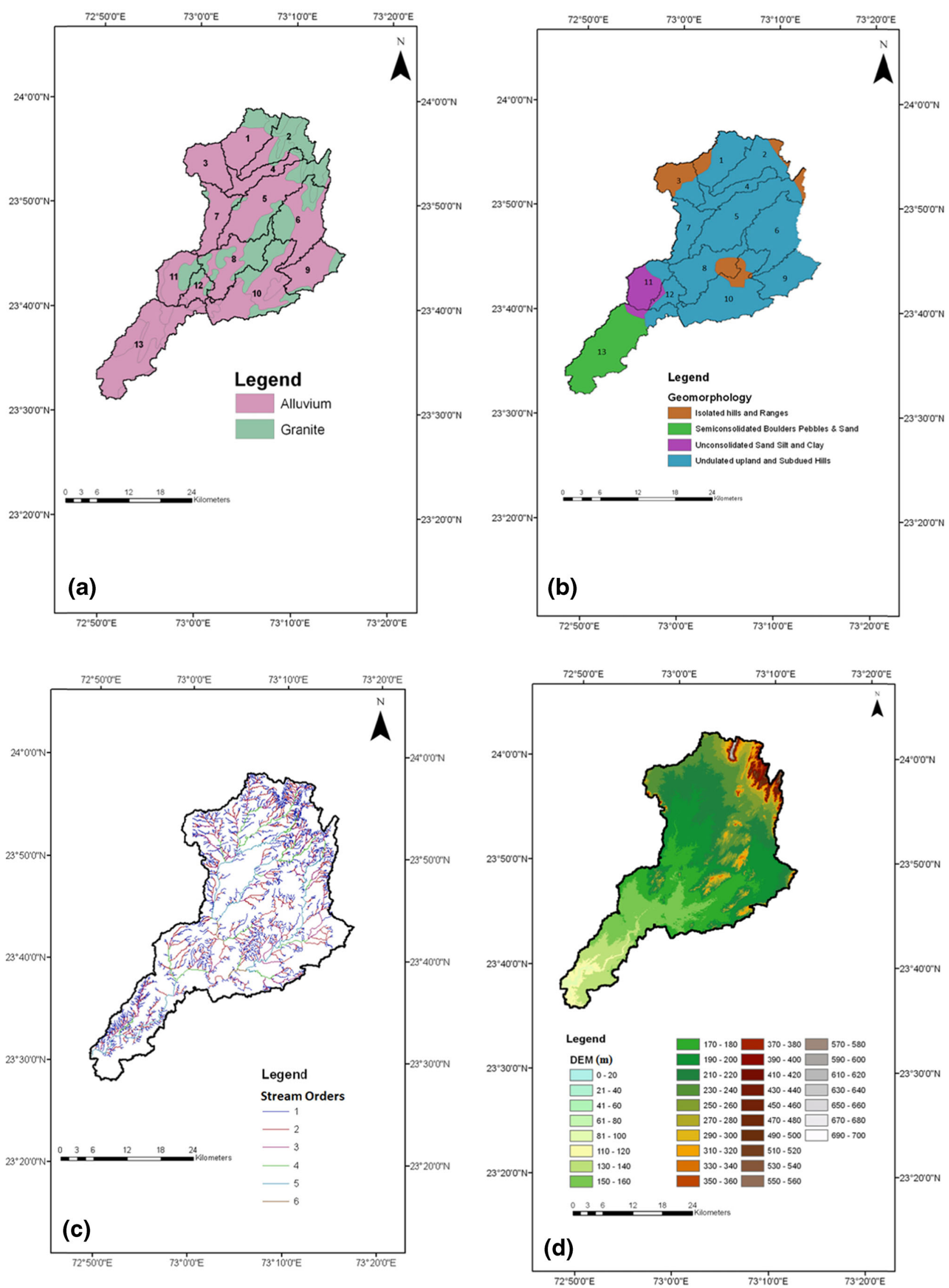

Figure 2. (a) Geology, (b) geomorphology, (c) drainage order, and (d) DEM of the study area. 
morphometric parameters are calculated using the equations given in Patel et al. (2013). Linear parameters have a direct relationship with erodability, which means higher the linear parameters, higher the erodability (Nooka Ratnam et al. 2005; Patel et al. 2012; Thakkar and Dhiman 2007). The watershed bearing highest value of the linear parameter is ranked 1 (responsible for highest erodability) followed by the second highest value (ranked 2) and so on. On the contrary, the shape parameters have inverse relation with linear parameters, which means lower the value of shape parameters, higher the erodability. Thus, the watershed bearing lowest value of the shape parameter is allotted as rank 1 and the second lowest as rank 2 and so on (Nooka Ratnam et al. 2005; Thakkar and Dhiman 2007; Patel et al. 2012). Compound factor was then computed by summing all the ranks of linear parameters as well as shape parameters. From the group of these mini-watersheds, highest prioritized rank was assigned to the mini-watershed having the lowest compound factor and so on.

In this study, first the weighted sum overlay analysis using spatial modeller tool is used to integrate the linear and shape parameters for deducing the compound factor map. To locate the water harvesting structures such as check dam, the following thematic layers - slope, drainage density, compound factor, and soil are generated. All the thematic layers are spatially co-registered to bring them in the same spatial reference frame. Hence, in the next step, image to image co-registration of all the geospatial datasets is performed. The SRTM DEM is used as base image to which all the thematic images are co-registered. During georeferencing, the positional root mean square error (RMSE)

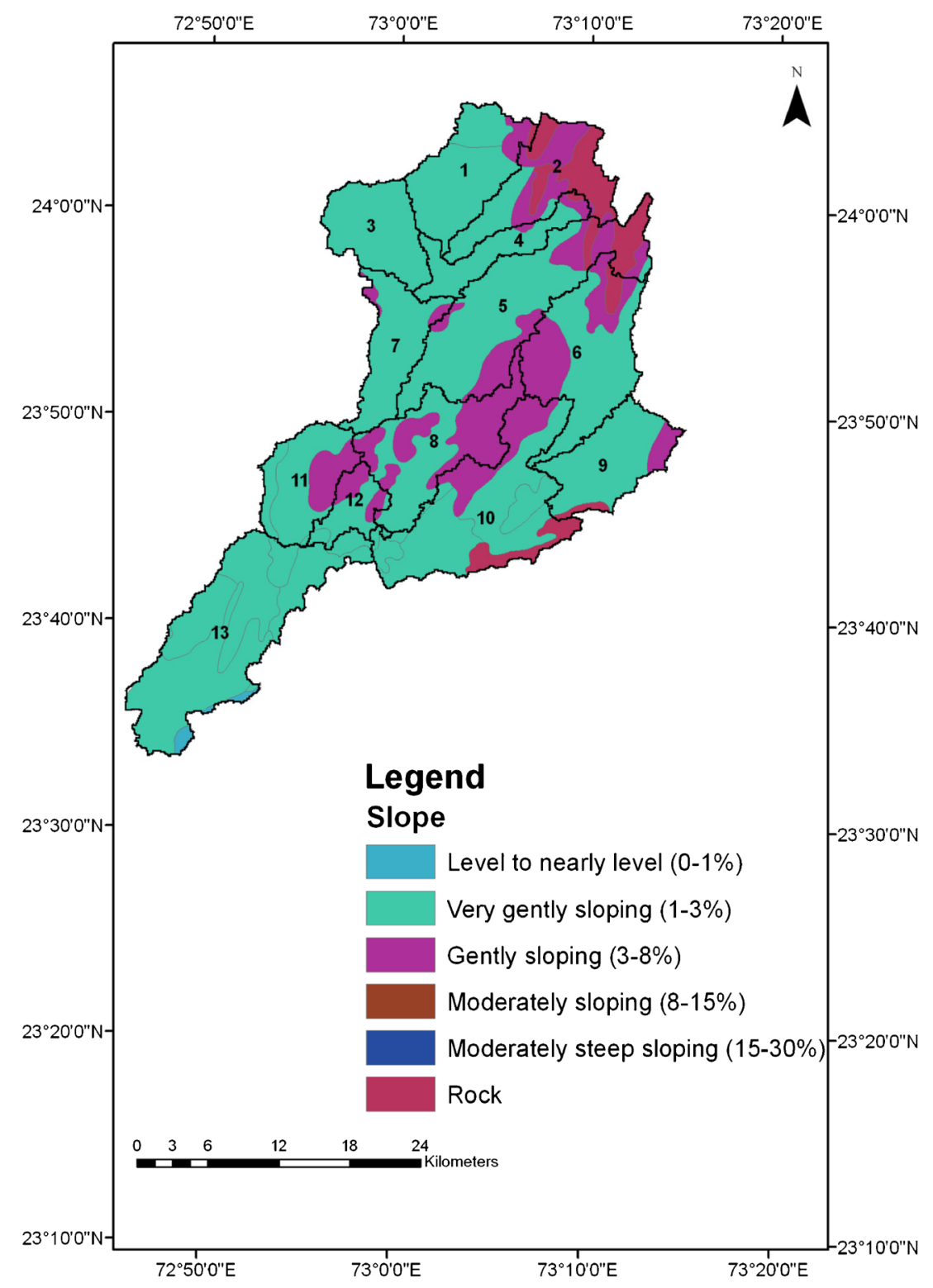

Figure 3. Slope of the study area. 
is used as an objective function, which here is less than $90 \mathrm{~m}$ (one pixel of SRTM DEM) in both $\mathrm{x}$ and y dimensions. The nearest neighbour method is used for co-registration with a common projection WGS 84, UTM Zone 44. The thematic maps used in this study are from different resources and have different spatial resolutions; hence all the GIS thematic layers are brought to a common scale by following a resampling method to match the spatial resolution of the SRTM DEM $(90 \mathrm{~m})$. The resampling of the GIS layers involved in the current study has been performed using the nearest neighbour method. Afterwards, the weighted overlay analysis using MCE technique is used to delineate the best possible locations for check dam creations. The details about the knowledge-based weight assignment and MCE are discussed briefly in section 2.4.

\subsection{Multi-criteria evaluation and weight assignment}

The knowledge-based weight assignment is carried out for each feature using the MCE. These assignments are carried out by using expert judgment, field survey as well as from literatures. The MCE is based on the Analytical Hierarchical Principle (AHP) given by Saaty $(1987,1995)$; and Saaty and Vargas (2001) and widely used by a number of researchers (Saaty and Shih 2009; Srivastava et al. 2010, 2012a; Song et al. 2012).

In MCE, a pair-wise comparison is used for the selection of preferences and here it is a $1 \rightarrow 9$ point based ranking scale as proposed by Saaty (1980) in which the scale 1 represents the least following to 9 in ascending order of importance. After pair-wise comparisons, the decision matrix is

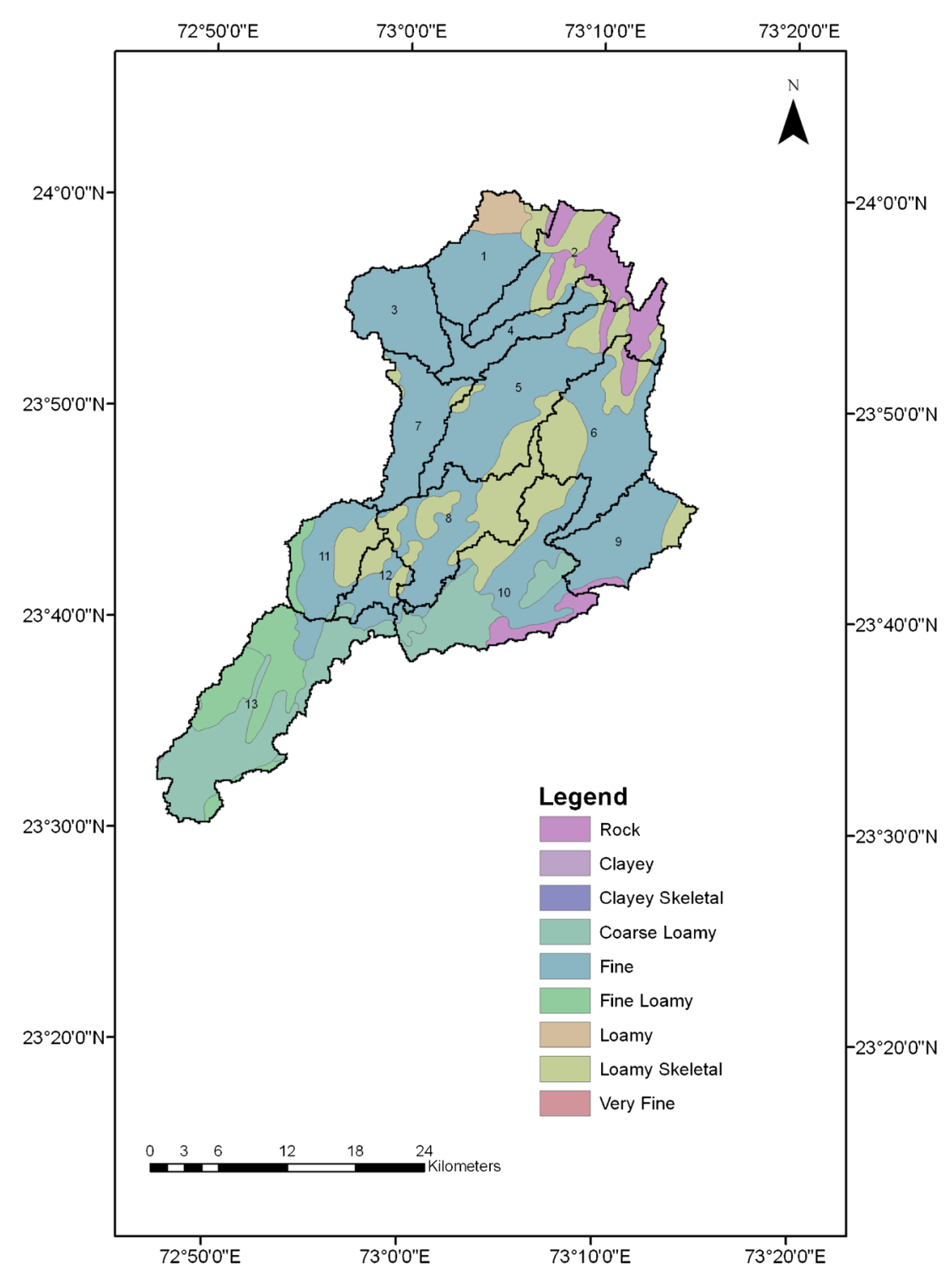

Figure 4. Soil map of the study area. 
obtained, which undergoes a linear algebra transformation. The consistency of the selection and the knowledge-based judgments involved is based on an eigen-value of the decision matrix. The final step is the estimation of consistency ratio (CR) (Saaty 1980). For CR estimation, the first step is the calculation of the consistency index (CI) (maximum eigen-value of the comparison matrix) and then division of CI by the random inconsistency index (RI) gives a CR index. The numerical basis of the MCE is represented through the equations (1-3) (figure 5).

MATLAB 10.0 is used to prepare the script that was used for analysing the data and generation of CR and CI ratio. The CR and CI are useful parameters for an effective decision-making process and precision of the weighting analysis. The CR is calculated to determine whether the evaluation is successful or not. A CR value of less than 0.1 indicates good consistency (Saaty and Vargas 2001) and if $\mathrm{CR}>0.1$, the weighting is inconsistent and needs to be reassessed (Gupta and Srivastava 2010). The priorities of the criteria are estimated by finding the principal eigenvector $\mathbf{e}$ of the matrix $\mathbf{M}$ as:

$$
\mathbf{M}_{\mathrm{e}}=\lambda_{\max } \mathbf{e}
$$

where $\lambda_{\max }$ is the largest eigenvalue of the matrix $\mathbf{M}$ and the corresponding eigenvector e. The CR can be calculated as:

$$
\mathrm{CR}=\frac{\mathrm{CI}}{\mathrm{RI}}
$$

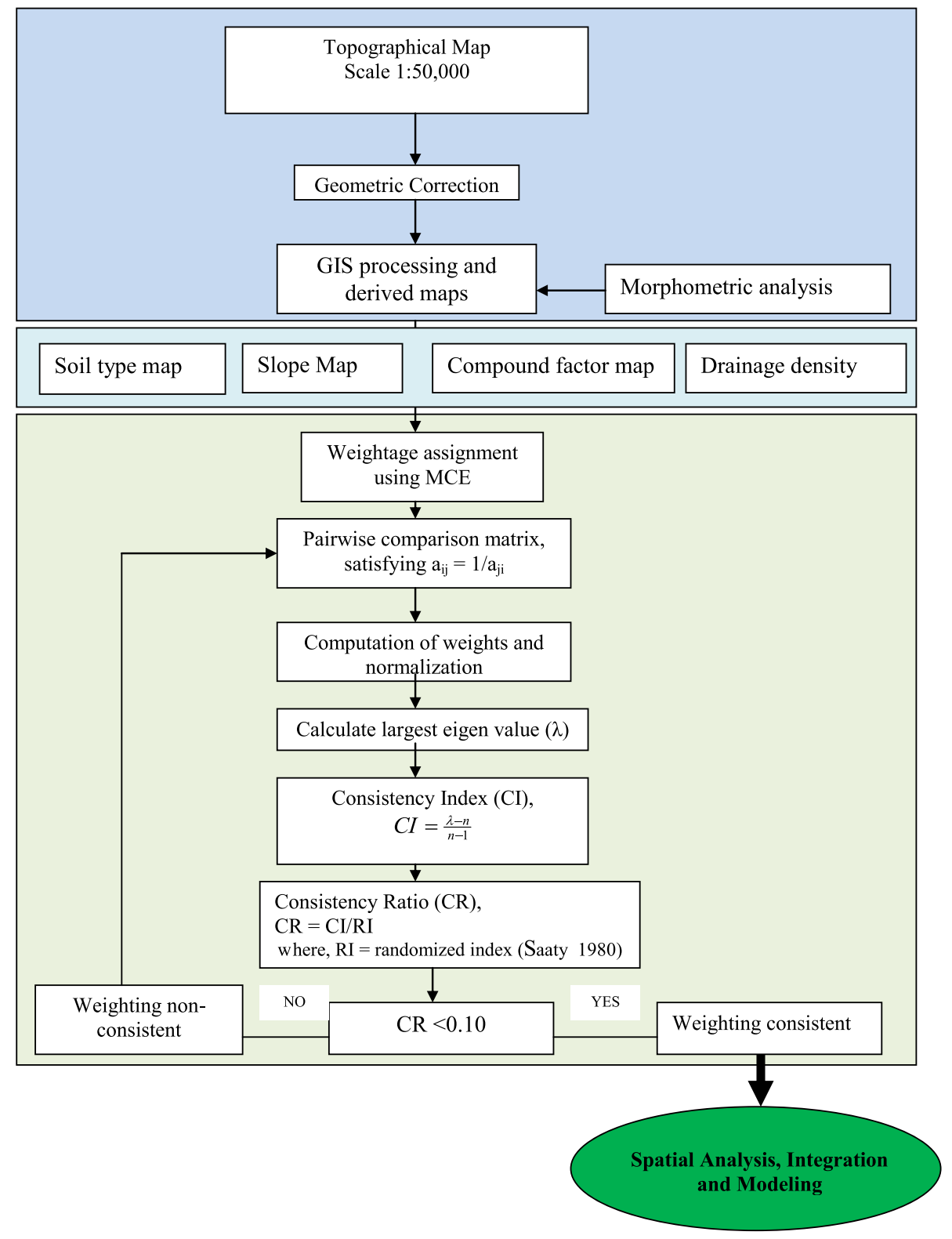

Figure 5. Flowchart depicting MCE analysis used in this study. 
where CI is defined as:

$$
\mathrm{CI}=\frac{\left(\lambda_{\max }-n\right)}{(n-1)}
$$

with $n$ being the number of selected parameters. The mean RI is obtained by averaging the CIs of many randomly-generated pair-wise comparison matrices (Saaty and Vargas 2001).

\section{Result and discussion}

The importance of the morphometric parameters and results obtained from morphometric analysis are discussed in the following sections. These parameters are calculated using the formulae given in (Nooka Ratnam et al. 2005; Patel et al. 2013; Patel et al. 2012) and the results are presented in tables $1-3$.

\subsection{Basic parameters}

Basic parameters which are important for morphometric analysis include drainage area, stream order, perimeter, stream and basin length. All the basic parameters are explained in the following subsections and represented through figure 6 .

\subsubsection{Drainage area $(A)$ and perimeter $(P)$}

The drainage area $(A)$ is an important watershed characteristic for hydrologic design and reflects the volume of water that can be generated from rainfall. The result shows that the watershed no. 13 covers the maximum area of $162.03 \mathrm{~km}^{2}$ while watershed no. 12 has minimum area of $25.64 \mathrm{~km}^{2}$. The basin perimeter $(P)$ can be represented as length of the line that defines the surface divide of the basin. The perimeters of watersheds are shown in table 2 .

\subsubsection{Total length of streams $(L)$ and stream order $(u)$}

Stream length is the addition of all stream lengths in a particular order. The number of streams of various orders in mini-watersheds was counted and measured lengths are shown in table 2 . These results facilitated the calculation of drainage density in the area. To describe the basins in quantitative terms, concept of stream order was introduced by Horton (1945); Strahler (1957, 1964). This concept is applied with the linear dimension of the stream length. The first order stream has no tributary and its flow depends entirely on the surface overland flow. Likewise the second-order stream is formed by the junction of two first-order streams. Among the 13 watersheds, 1, 3, 8, and 13 are the watersheds having 216, 151, 239, and 478 streams respectively as shown in table 2 . In watershed number 1, out of 216 streams, 114 belong to stream order I, whereas none has stream order V. In watershed numbers 8,9 streams belong to order VI, whereas 18 streams in watershed number 13 belong to stream order IV.

\subsubsection{Basin length $\left(L_{b}\right)$}

The basin length $\left(L_{b}\right)$ is important in hydrologic computations and is proportional to the drainage area. Basin length is usually defined as the distance measured along the main channel from the watershed outlet to the basin divide. Since the channel does not extend to the basin-divide, it is necessary to extend a line from the end of the channel to the basin-divide following a path where the greatest volume of water would travel. Thus, the length is measured along the principal flow path. Basin length is the basic input parameter to count the major shape parameters. In the result, basin length varies between 8.28 and $23.62 \mathrm{~km}$, indicated in table 2 .

Table 1. Stream order of Hathmati watersheds.

\begin{tabular}{lrrrrrrr}
\hline $\begin{array}{l}\text { Watershed } \\
\text { no. }\end{array}$ & I Order & II Order & III Order & IV Order & V Order & VI Order & $\begin{array}{c}\text { Total no. } \\
\text { of streams }\end{array}$ \\
\hline 1 & 114 & 61 & 31 & 17 & & & 216 \\
2 & 191 & 105 & 39 & 28 & & 355 \\
3 & 82 & 40 & 30 & 10 & 2 & & 151 \\
4 & 70 & 31 & 9 & 20 & 19 & & 147 \\
5 & 202 & 95 & 40 & 33 & 20 & & 388 \\
6 & 128 & 69 & 37 & 6 & 26 & & 261 \\
7 & 59 & 37 & 10 & 2 & 13 & & 116 \\
8 & 118 & 68 & 30 & 15 & 2 & 9 & 239 \\
9 & 27 & 15 & 7 & 7 & & & 56 \\
10 & 178 & 85 & 69 & 15 & 15 & 5 & 359 \\
11 & 42 & 24 & 3 & 14 & & & 81 \\
12 & 45 & 24 & 13 & 7 & & & 478 \\
13 & 241 & 112 & 54 & 18 & 55 & & \\
\hline
\end{tabular}




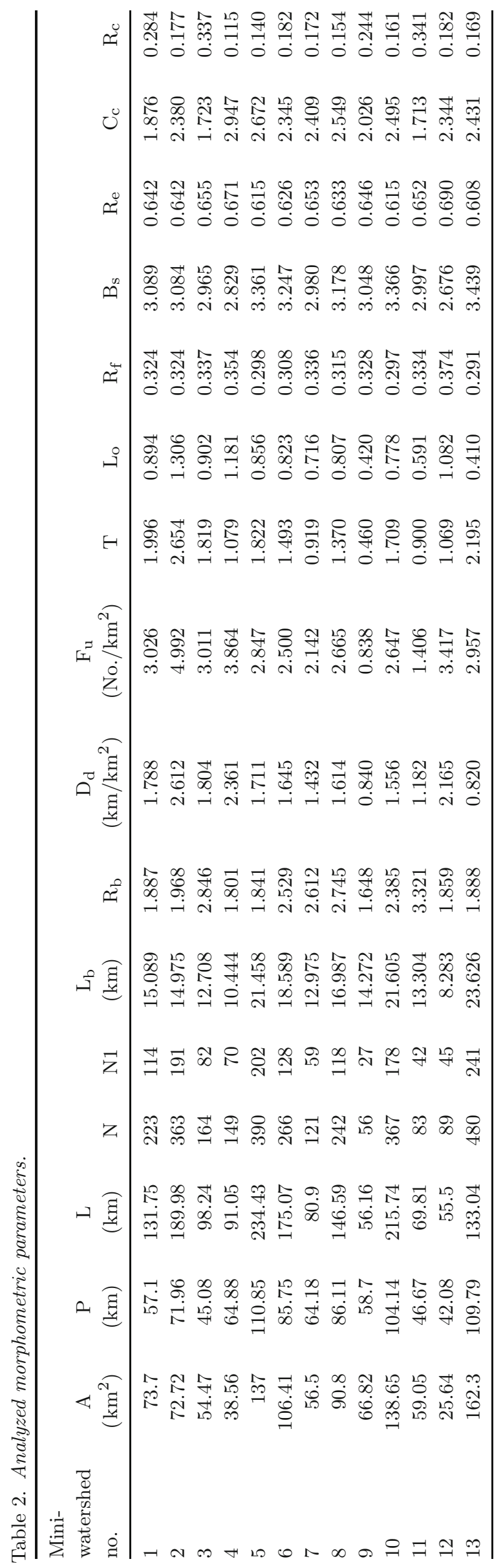

\subsection{Linear parameters}

Linear parameters include bifurcation ratio, drainage density, stream frequency, texture ratio, and length of overland flow (figure 6).

\subsubsection{Bifurcation ratio $\left(R_{b}\right)$ and drainage density $\left(D_{d}\right)$}

It is the ratio of the number of streams of a given order to the number of streams of the next higher order (Schumm 1956). Lower $R_{b}$ values are the characteristics of structurally less disturbed watersheds without any distortion in drainage pattern (Nag 1998). Table 2 shows that in bifurcation ratios $\left(R_{b}\right)$ of Hathmati watersheds, watershed number 9 (figure 6) has the least bifurcation ratio of 1.64 and number 11 has maximum ratio of 3.32 . Drainage density is the ratio of the total length of streams within a watershed to the total area of the watershed; thus $D_{d}$ has the units of reciprocal of the length $(1 / L)$. A high value of the drainage density indicates a relatively high density of streams and thus a rapid storm response. The values of $D_{d}$ are shown in table 2 .

\subsubsection{Stream frequency $\left(F_{u}\right)$, texture ratio $(T)$ and length of overland flow $\left(L_{o}\right)$}

Stream frequency/channel frequency $\left(F_{u}\right)$ is the total number of stream segments of all orders per unit area (Horton 1932). Low value of stream frequency indicates low runoff value and increase in stream population. The value of stream frequency ranges from 0.83 to 4.99 , as shown in table 2 . The texture ratio can be defined as the ratio of total number of streams of first order to the perimeter of the basin. The value of the texture ratio ranges from 0.46 to 2.65 as shown in table 2. $L_{o}$ is the length of water over the ground before it gets merged into definite stream channels and is found equal to half of the drainage density (Horton 1945). It has inverse relation to the average channel slope. Table 3 indicates the length of overland flow for Hathmati watersheds.

\subsection{Shape parameters}

The shape parameters include form factor, shape factor, elongation ratio, compactness ratio, and circulatory ratio.

\subsubsection{Shape factor $\left(B_{s}\right)$ and elongation ratio $\left(R_{e}\right)$}

The shape factor, $B_{s}$ can be defined as the ratio of the square of the basin length to the area of the basin (Horton 1945) and is found to be inversely 
Table 3. Calculation of compound factor and prioritized ranks.

\begin{tabular}{lrrrrrrrrrrrr}
\hline Watershed & & & & & & & & & \multicolumn{2}{c}{$\begin{array}{c}\text { Compound } \\
\text { factor }\end{array}$} & $\begin{array}{c}\text { Prioritized } \\
\text { ranks }\end{array}$ \\
\hline 1 & $\mathrm{R}_{\mathrm{b}}$ & $\mathrm{D}_{\mathrm{d}}$ & $\mathrm{F}_{\mathrm{u}}$ & $\mathrm{T}$ & $\mathrm{L}_{\mathrm{o}}$ & $\mathrm{R}_{\mathrm{f}}$ & $\mathrm{B}_{\mathrm{s}}$ & $\mathrm{R}_{\mathrm{e}}$ & $\mathrm{C}_{\mathrm{c}}$ & $\mathrm{R}_{\mathrm{c}}$ & 3 \\
2 & 9 & 5 & 4 & 3 & 5 & 6 & 8 & 6 & 3 & 11 & 6.0 & 3 \\
3 & 7 & 1 & 1 & 1 & 1 & 7 & 7 & 7 & 7 & 7 & 4.6 & 1 \\
4 & 2 & 4 & 5 & 5 & 4 & 11 & 3 & 11 & 2 & 12 & 5.9 & 2 \\
5 & 12 & 2 & 2 & 9 & 2 & 12 & 2 & 12 & 13 & 1 & 6.7 & 5 \\
6 & 11 & 6 & 7 & 4 & 6 & 3 & 11 & 3 & 12 & 2 & 6.5 & 4 \\
7 & 5 & 7 & 10 & 7 & 7 & 4 & 10 & 4 & 6 & 8 & 6.8 & 6 \\
8 & 4 & 10 & 11 & 11 & 10 & 10 & 4 & 10 & 8 & 6 & 8.4 & 11 \\
9 & 3 & 8 & 8 & 8 & 8 & 5 & 9 & 5 & 11 & 3 & 6.8 & 7 \\
10 & 13 & 12 & 13 & 13 & 12 & 8 & 6 & 8 & 4 & 10 & 9.9 & 13 \\
11 & 6 & 9 & 9 & 6 & 9 & 2 & 12 & 2 & 10 & 4 & 6.9 & 8 \\
12 & 1 & 11 & 12 & 12 & 11 & 9 & 5 & 9 & 1 & 13 & 8.5 & 12 \\
13 & 10 & 3 & 3 & 10 & 3 & 13 & 1 & 13 & 5 & 9 & 7.0 & 9 \\
\hline & 8 & 13 & 6 & 2 & 13 & 1 & 13 & 1 & 9 & 5 & 7.1 & 10 \\
\hline
\end{tabular}

related with the form factor $\left(R_{f}\right)$. Shape factor lies between 2.67 and 3.43, which indicates the elongated shape of basin. A circular basin is more efficient in runoff discharge than an elongated basin (Singh and Singh 1997). The elongated ratio varies between 0.6 and 1.0 over a wide variety of climatic and geologic types. Typical values are close to 1.0 for regions of very low relief and are between 0.6 and 0.8 for regions of strong relief and steep ground slope (Strahler 1964). The lower value of the elongation ratio indicates that the particular mini-watershed is more elongated than others. The elongation value can be grouped into three categories, namely circular basin $\left(R_{e}>0.9\right)$, oval basin $\left(R_{e}: 0.9-0.8\right)$, less elongated basin $\left(R_{e}<0.7\right)$. In this study (table 2 ), the values obtained are less than 0.7 and hence it is concluded that the basins are elongated in shape.

\subsubsection{Form factor $\left(R_{f}\right)$}

The form factor can be defined as the ratio of the area of the basin to square of the basin length (Horton 1945). The value of the form factor is always less than 0.785 for a perfectly circular basin (Chopra et al. 2005; Patel et al. 2012). The basin will be more elongated, if smaller value of form factor is obtained. The basin with high form factors generally has peak flow of shorter duration, whereas, elongated basin with low form factors has peak flow of longer duration. In the present case, value of form factor is 0.291 for watershed number 13 , which is lowest in the group and 0.374 for number 12 which is found to be highest in comparison to all watersheds (table 2). The results indicate an elongated shape of the basin with low form factor and thus a flatter peak flow for longer duration can be obtained.

\subsubsection{Compactness coefficient $\left(C_{c}\right)$}

Compactness coefficient (Gravelius Index) can be represented as ratio of basin perimeter to the circumference of a circular area which equals the area of watershed. This factor is indirectly related with the elongation of the basin area (Patel et al. 2012) and influences erodibility. Lower values of this parameter indicate more elongated basin and lesser erosion, while higher values indicate less elongation and higher erosion. In this study, the highest value is obtained as 2.94, while the lowest is 1.71 as shown in table 2 .

\subsubsection{Circularity ratio $\left(R_{c}\right)$}

Circularity ratio is a ratio of basin area $(A)$ to the area of circle having the same circumference as the perimeter of the basin (Miller 1953). It is affected by the length and frequency of the streams, geological structures, land use/land cover, climate, relief, and slope of the basin. If the circularity ratio of the main basin is low, a slow discharge from the basin will be obtained and so possibility of erosion will be less. In present study, maximum value of $R_{c}(0.34)$ is obtained for watershed number 11, while watershed number 4 is the lowest, with the value of 0.11 .

\subsection{Compound factor (CF)}

Compound factor is computed by summing all the ranks of linear parameters as well as shape parameters and then divided by the number of parameters. From the group of delineated mini-watersheds, highest rank is assigned to the mini-watershed having the lowest compound factor and vice versa (Nooka Ratnam et al. 2005; Patel et al. 2012) (table 3). From the analysis, the watershed number 

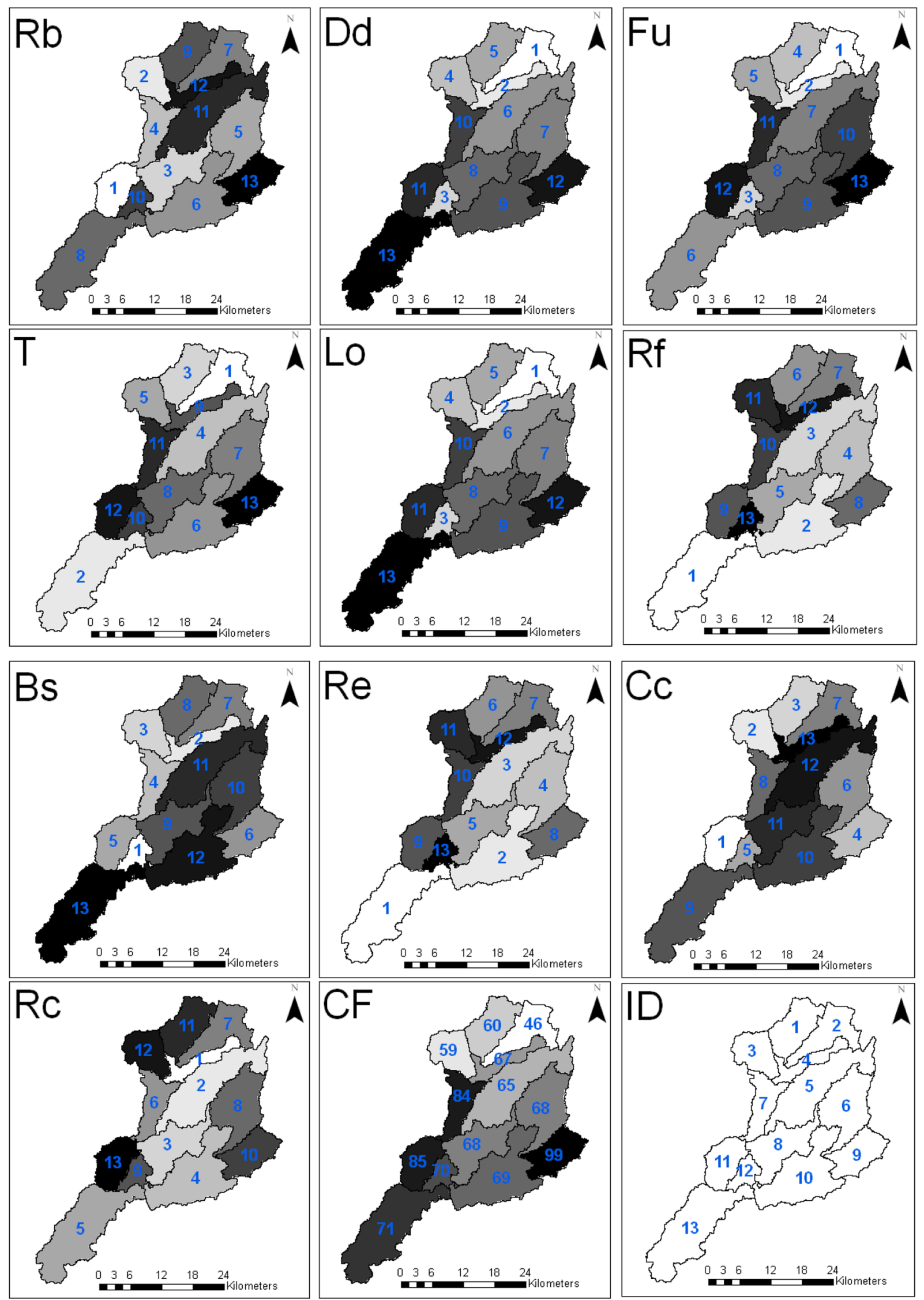

Figure 6. Parameters $R_{b}, D_{d}, F_{u}, T, L_{o}, R_{f}, B_{s}, R_{e}, C_{c}, R_{c}$ compound factor (CF) and watersheds ID. 
2 is given rank 1 with least compound factor value of 4.6 followed by watersheds 3 and 1 with second and third ranks, respectively. The values of compound factor and respective rank of all mini-watersheds are shown in table 3.

\subsection{MCE and water harvesting structure sites}

Water harvesting structures like check dams depend on the morphometric parameters. Four important parameters such as soil type, drainage density, slope, and compound factor rank map are selected from the datasets to delineate the best zones for check dam positioning. These four parameters are chosen based on their hydrologic response such as infiltration, water residence time, velocity of water, and the soil erodability. The field survey and literature (Nooka Ratnam et al. 2005; Patel et al. 2012) are utilized for assigning a rating to the parameters chosen. The rating factor varies from $1 \rightarrow 9$. A higher rating indicates that the factor has a high degree of influence for check dam positioning, whereas influence factors indicate the overall weight of the parameters for prioritization of mini-watersheds. The consistency in weighting assignment is provided after AHP-MCE analysis.

Table 4. Pair comparison matrix of features.

\begin{tabular}{lccccc}
\hline & $\begin{array}{c}\text { Compound } \\
\text { factor }\end{array}$ & Slope & $\begin{array}{c}\text { Drainage } \\
\text { density }\end{array}$ & $\begin{array}{c}\text { Soil } \\
\text { type }\end{array}$ & $\begin{array}{c}\text { Normalized } \\
\text { weights }\end{array}$ \\
\hline Compound factor & 1 & 3 & 5 & 7 & 55.8 \\
Slope & $1 / 3$ & 1 & 3 & 5 & 26.4 \\
Drainage density & $1 / 5$ & $1 / 3$ & 1 & 3 & 12.2 \\
Soil type & $1 / 7$ & $1 / 5$ & $1 / 3$ & 1 & 5.6 \\
CR & 0.043 & & & & \\
\hline
\end{tabular}

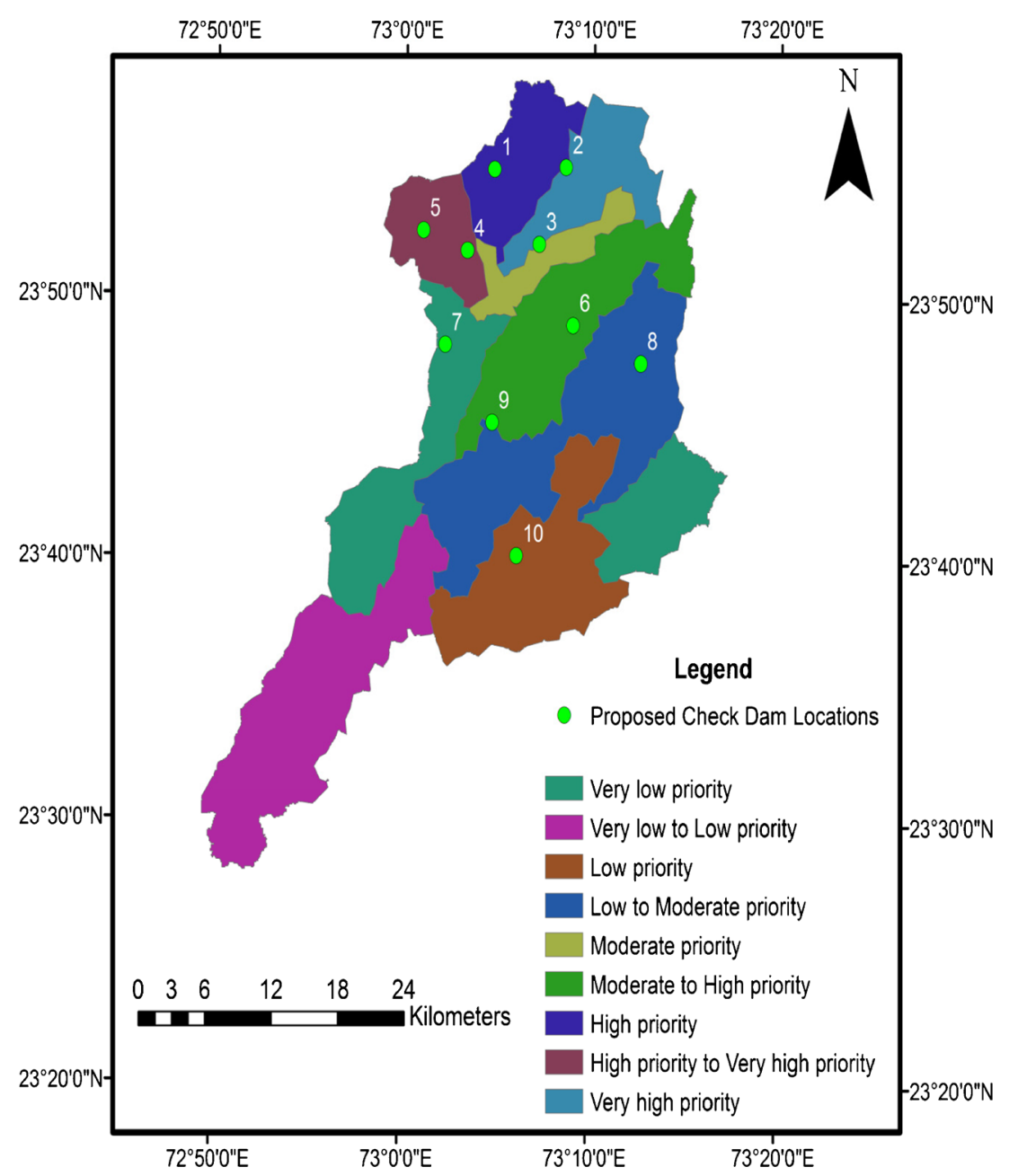

Figure 7. Prioritized Hathmati watersheds and proposed water harvesting structures. 
For the check dam positioning, $\mathrm{CF}$ is given the highest normalized weight of $55.8 \%$, followed by soil type $(26.4 \%)$, drainage density $(12.2 \%)$ and slope $(5.6 \%)$. The CR $(0.043)$ of the data showed that the weights taken for analysis are precise for weighted overlay analysis (table 4). During

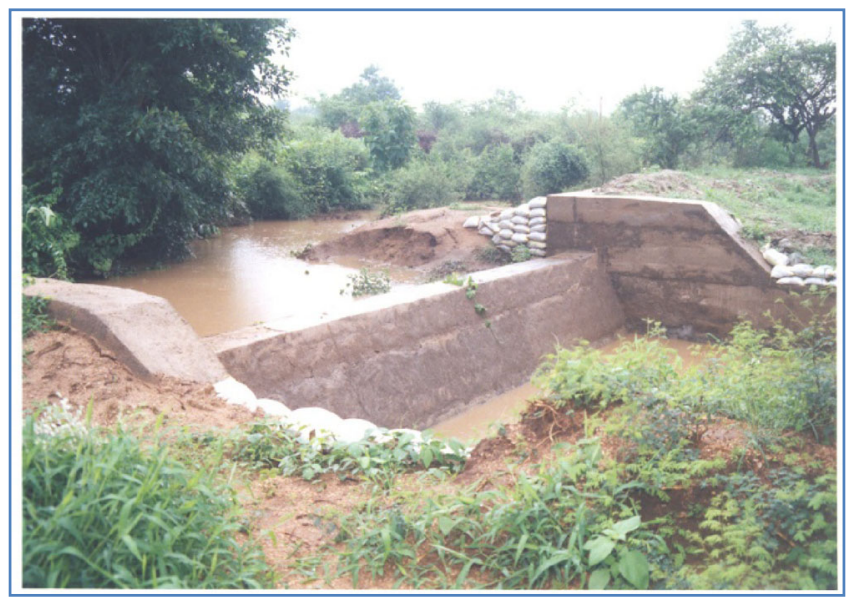

(a)

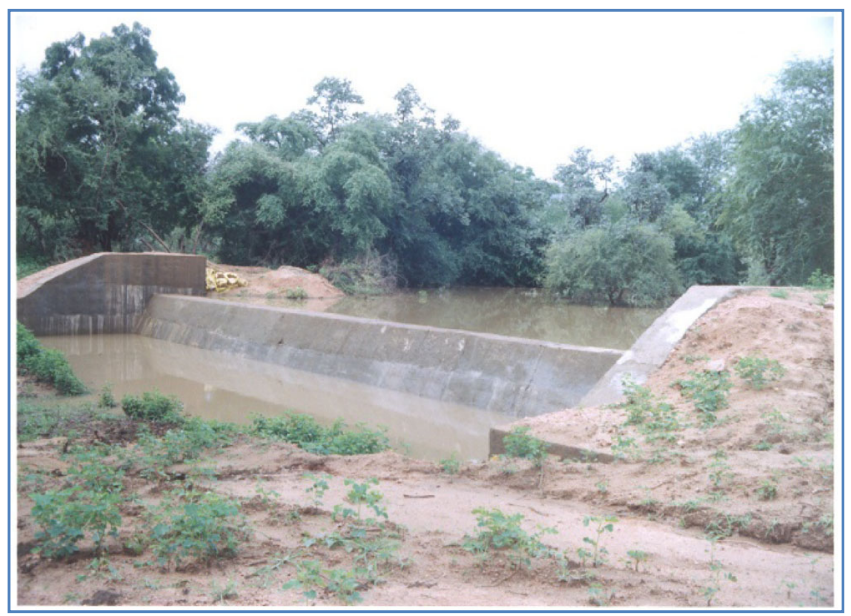

(b)

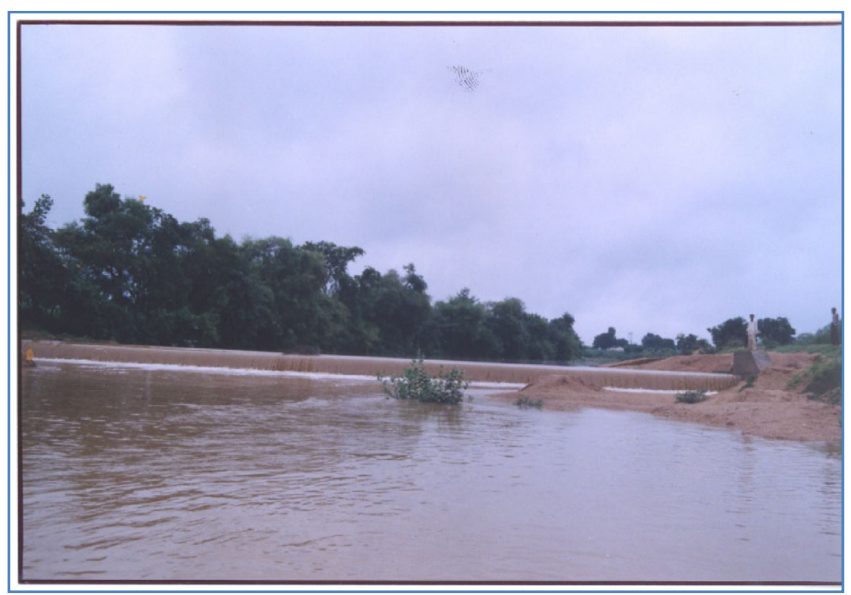

(c)

Figure 8. Photographs of check dam constructed on the study site. (a) Check dam 3, (b) check dam 4, and (c) check dam 6 .
Check Dam Positioning (CDP), three very small mini-watersheds were merged with the downstream watersheds, resulting in reduction of miniwatersheds from 13 to 10 . The relation for CDP can be expressed as equation 4 .

$$
\begin{aligned}
\mathrm{CDP}= & 55.8 \times \mathrm{CF}+26.4 \times \text { soil type }+12.2 \\
& \times \text { drainage density }+5.6 \times \text { slope }
\end{aligned}
$$

After above-mentioned rigorous analysis and delineation of the check dam location, nearly 10 check dam sites are proposed where water harvesting structures can be constructed (figure 7). All the check dam sites have been surveyed for their feasibility. At some locations check dams are already constructed as shown in the photographs (figure 8). The sites are found more frequently distributed towards the north-western side. The check dam locations clearly suggest a preponderance and congregation of sites towards the moderate elevations. Most of them are located away from the Hathmati river and found towards the densely vegetated area.

It is very likely that the future water harvesting sites explorations might be very fruitful, if the methodology followed in this work is also included in the guiding principles. The RS and GIS data matched well with the field-survey, validating the principal foundation of site identification and characterisation, as the model developed is in good agreement with the field survey of the area. The research and survey showed that the role of geomorphology and topography in determining the choices of the water harvesting structure positioning are very essential, and provide efficient results when combined with AHP based MCE. The applications of proposed methodology in the near future would save ample amount of time, money, and other important relevant resources.

\section{Conclusions}

The study demonstrated that SRTM and topographical maps along with GIS is a very useful and efficient technique for delineating miniwatersheds and their prioritization. In this work, the entire area has been divided into several miniwatersheds and prioritization has been carried out considering various morphometric parameters. On the basis of priority and weighted sum analysis of each thematic map, the possible locations of check dams are proposed in the prioritized watersheds after AHP-MCE based analysis. From the results, it can be realistically assumed that the watersheds that receive a low priority for restoration are likely to have a high level of environmental quality and stability. The datasets generated are successfully used for the water harvesting structure positioning, by combining the results of the four 
primary thematic layers having different weights. The outcomes are validated against the field survey data which indicate a close agreement, and in turn demonstrate the usefulness of predictive modelling for difficult terrains. From the results, in the order of higher to lower, the watersheds can be ranked as $2,3,1,5,4,6,8$ and 10 for CDP. Check dam structures can be built on the proposed locations to check the excessive water and provide support for soil and water conservation.

It is expected that this work will open new avenues in the field of AHP-MCE in morphometric analysis and its applicability to watershed management. Researchers in future can select specific locations based on the proposed methodology before envisaging a broad survey or exploration work that necessitate a lot of effort and finances. Therefore, this kind of research would reduce the total cost of the project and provide maximum output. Bearing in mind the results from the present study, more advanced and sophisticated models will be prepared in near future by extensively utilising the other satellite data sources.

\section{Acknowledgements}

The authors would like to express their sincere thanks to Bhaskaracharya Institute for Space Applications and Geo-informatics (BISAG), Survey of India (SOI), National Bureau of Soil Survey (NBSS), State Water Commission (SWC), and Gujarat Irrigation Department for providing necessary facilities and support during the study period.

\section{References}

Aher P, Adinarayana J and Gorantiwar S 2014 Quantification of morphometric characterization and prioritization for management planning in semi-arid tropics of India: A remote sensing and GIS approach; J. Hydrol. 511 850-860.

Bali R, Agarwal K, Nawaz Ali S, Rastogi S and Krishna K 2012 Drainage morphometry of Himalayan glacio-fluvial basin, India: Hydrologic and neotectonic implications; Environ. Earth Sci. 66 1163-1174.

Banerjee R and Srivastava P K 2014 Remote sensing based identification of painted rock shelter sites: Appraisal using Advanced Wide Field Sensor, Neural Network and Field Observations; In: Remote Sensing Applications in Environmental Research, Springer, pp. 195-212.

Betson R P 1964 What is watershed runoff; J. Geophys. Res. 69 1541-1552.

Black P E 2005 Watershed hydrology; Wiley Online Library.

Buttenfield B P and Mackaness W A 1991 Visualization; In: Geographical Information Systems 1 427-443.

Chopra R, Dhiman R D and Sharma P 2005 Morphometric analysis of sub-watersheds in Gurdaspur district, Punjab using remote sensing and GIS techniques; J. Indian Soc. Remote Sens. 33 531-539.
Chow V T 1964 Handbook of applied hydrology; Section 8 8-61.

Chowdary V, Ramakrishnan D, Srivastava Y, Chandran V and Jeyaram A 2009 Integrated water resource development plan for sustainable management of Mayurakshi watershed, India using remote sensing and GIS; Water Resour. Manag. 23 1581-1602.

Edet A, Okereke C, Teme S and Esu E 1998 Application of remote-sensing data to groundwater exploration: A case study of the Cross River State, southeastern Nigeria; Hydrogeol. J. 6 394-404.

Essiet E 1990 A comparison of soil degradation under smallholder farming and large-scale irrigation land use in Kano State, northern Nigeria; Land Degradation 85 Development 2 209-214.

GEC 1992 Gujarat Ecology Commission Forest \& Environment Department, Government of Gujarat, India, http:// wwwgecgovin/gecweb/homeasp.

Gupta M and Srivastava P K 2010 Integrating GIS and remote sensing for identification of groundwater potential zones in the hilly terrain of Pavagarh, Gujarat, India; Water Int. 35 233-245.

Horton R E 1932 Drainage basin characteristics; Trans. Am. Geophys. Union 13 350-361.

Horton R E 1945 Erosional development of streams and their drainage basins: Hydrophysical approach to quantitative morphology; Geol. Soc. Am. Bull. 56 275-370.

IMSD 1995 Integrated Mission for Sustainable Development: Technical Guidelines, NRSA, Hyderabad, India, pp. 1-127.

Javed A, Khanday M Y and Ahmed R 2009 Prioritization of sub-watersheds based on morphometric and land use analysis using remote sensing and GIS techniques; $J$. Indian Soc. Remote Sens. 37 261-274.

Javed A, Khanday M Y and Rais S 2011 Watershed prioritization using morphometric and land use/land cover parameters: A remote sensing and GIS based approach; J. Geol. Soc. India 78 63-75.

Kessler W B, Salwasser H, Cartwright C W and Caplan J A 1992 New perspectives for sustainable natural resources management; Ecol. Appl. 2 221-225.

Khan M, Gupta V and Moharana P 2001 Watershed prioritization using remote sensing and geographical information system: A case study from Guhiya, India; J. Arid Environ. 49 465-475.

MacEachren A M and Taylor D R F 1994 Visualization in modern cartography; vol. 2, Pergamon Press.

Magesh N S, Jitheshlal K V, Chandrasekar N and Jini K V 2012 GIS based morphometric evaluation of Chimmini and Mupily watersheds, parts of Western Ghats, Thrissur District, Kerala, India; Earth Sci. Inform. 5 111-121, doi: 10.1007/s12145-012-0101-3.

Miller V C 1953 A quantitative geomorphic study of drainage basin characteristics in the clinch mountain area Virginia and Tennessee, DTIC Document.

Mukherjee S, Shashtri S, Singh C, Srivastava P and Gupta M 2009 Effect of canal on land use/land cover using remote sensing and GIS; J. Indian Soc. Remote Sens. $\mathbf{3 7}$ $527-537$.

Nag S K 1998 Morphometric analysis using remote sensing techniques in the Chaka sub-basin, Purulia district, West Bengal; J. Indian Soc. Remote Sens. 26(1-2) 69-76.

Nooka Ratnam K, Srivastava Y, Venkateswara Rao V, Amminedu E and Murthy K S R 2005 Check dam positioning by prioritization of micro-watersheds using SYI model and morphometric analysis - Remote sensing and GIS perspective; J. Indian Soc. Remote Sens. 33 25-38.

Osborne L L and Wiley M J 1988 Empirical relationships between land use/cover and stream water quality in an agricultural watershed; J. Environ. Manag. 26 9-27. 
Patel D P, Gajjar C and Srivastava P K 2013 Prioritization of Malesari mini-watersheds through morphometric analysis: A remote sensing and GIS perspective; Environ. Earth Sci. 69 2643-2656, doi: 10.1007/s12665-012-2086-0.

Patel D P and Srivastava P K 2013 Flood Hazards Mitigation Analysis using Remote Sensing and GIS: Correspondence with Town Planning Scheme; Water Resour. Manag. 27 2353-2368, doi: 10.1007/s11269-013-0291-6.

Patel D P 2012 Flood assessment by integrated hydrological modeling with RS and GIS in water resources management, PhD Thesis, Gujarat University.

Patel D P, Dholakia M B, Naresh N and Srivastava P K 2012 Water harvesting structure positioning by using geo-visualization concept and prioritization of miniwatersheds through morphometric analysis in the Lower Tapi Basin; J. Indian Soc. Remote Sens. 40 299-312.

Saaty T L 1980 The Analytic Hierarchy Process; McGraw Hill, New York.

Saaty T L 1987 Rank generation, preservation, and reversal in the analytic hierarchy decision process; Decision Sciences 18 157-177.

Saaty T L 1995 Transport planning with multiple criteria: The analytic hierarchy process applications and progress review; J. Adv. Transport 29 81-126.

Saaty T L and Shih H S 2009 Structures in decision making: On the subjective geometry of hierarchies and networks, European; J. Operational Res. 199 867-872.

Saaty T L and Vargas L G 2001 Models, methods, concepts $\&$ applications of the analytic hierarchy process; vol. 34, Springer.

Schumm S A 1956 Evolution of drainage systems and slopes in badlands at Perth Amboy, New Jersey; Geol. Soc. Am. Bull. 67 597-646.

Singh J, Singh D and Litoria P 2009 Selection of suitable sites for water harvesting structures in Soankhad watershed, Punjab using remote sensing and geographical information system (RS\&GIS) approach - A case study; $J$. Indian Soc. Remote Sens. 37 21-35.

Singh S and Singh M 1997 Morphometric analysis of Kanhar river basin; Nat. Geogr. J. India 43 31-43.

Song J, Ma S, Gao S, Wang Y and Cui Y 2012 Application of analytical hierarchy process and fuzzy synthetic evaluation in benefit assessment about high-level talents cultivation in Hebei province; In: International Conference on Information Management, Innovation Management and Industrial Engineering (ICIII), IEEE, pp. 210213.

Srivastava P K, Mukherjee S and Gupta M 2010 Impact of urbanization on land use/land cover change using remote sensing and GIS: A case study; Int. J. Ecol. Economics and Statistics 18 106-117.

Srivastava P, Mukherjee S, Gupta M and Singh S 2011 Characterizing monsoonal variation on water quality index of River Mahi in India using geographical information system; Water Quality Exposure and Health 2 193-203.

Srivastava P, Gupta M and Mukherjee S 2012a Mapping spatial distribution of pollutants in groundwater of a tropical area of India using remote sensing and GIS; Applied Geomatics 4 21-32, doi: 10.1007/s12518-011-0072-y.

Srivastava P K, Kiran G, Gupta M, Sharma N and Prasad K 2012 b A study on distribution of heavy metal contamination in the vegetables using GIS and analytical technique; Int. J. Ecol. Devel. 21 89-99.

Srivastava P K, Han D, Gupta M and Mukherjee S 2012c Integrated framework for monitoring groundwater pollution using a geographical information system and multivariate analysis; Hydrol. Sci. J. 57 1453-1472.

Srivastava P K, Singh S K, Gupta M, Thakur J K and Mukherjee S 2013 Modeling impact of land use change trajectories on groundwater quality using remote sensing and GIS; Environ. Eng. Manag. J. 12 2343-2355.

Strahler A N 1957 Quantitative analysis of watershed geomorphology; Trans. Am. Geophys. Union 38 913-920.

Strahler A N 1964 Quantitative geomorphology of drainage basin and channel networks; Handbook of Applied Hydrology.

Thakkar A K and Dhiman S 2007 Morphometric analysis and prioritization of miniwatersheds in Mohr watershed, Gujarat using remote sensing and GIS techniques; J. Indian Soc. Remote Sens. 35 313-321.

Yadav S K, Singh S K, Gupta $M$ and Srivastava P K 2014 Morphometric analysis of upper Tons basin from northern foreland of peninsular India using CARTOSAT satellite and GIS; Geocarto International, doi: 101080/101060492013868043:1-20. 